\title{
Modalidades autobiográficas en Campaña en el Ejército Grande de Domingo Faustino Sarmiento
}

\author{
GONZALO OYOLA*
}

A la Dra. Teresa Basile

Resumen:

La recurrencia del argumento crítico acerca del carácter autobiográfico que estaría presente en los escritos de Domingo Faustino Sarmiento instaló la pregunta respecto de la posibilidad de esbozar una matriz autobiográfica en la producción sarmientina, susceptible de funcionar como una máquina de lectura para un texto que, como Campaña en el Ejército Grande aliado de Sud América, juega en los bordes de las leyes de la autobiografía. El recorrido por otros textos de Sarmiento - fundamentalmente Recuerdos de provinciapermitió deslindar una serie de procedimientos que organizaban un lugar de enunciación desde donde el locutor hablaba de sí mismo a través de un relato que tomaba la forma de una crítica de su presente narrado como la barbarie de los caudillos. La configuración discursiva de esta subjetividad que (se) escribe mostró su ligazón a un proyecto de Estado, que venía a fundir el yo de la enunciación con la constitución de una imagen de la comunidad plasmada en la dicotomía civilización frente a barbarie.

Palabras clave:

Domingo Faustino Sarmiento, literatura argentina, siglo XIX, modalidades autobiográficas, géneros del yo, Campaña en el Ejército Grande aliado de Sud América, autobiografía, autofiguración, Juan Bautista Alberdi, polémica entre Sarmiento y Alberdi.

* Catedrático de Teoría Literaria I y II del Centro de Estudios de Teoría y Crítica Literaria, de la Universidad Nacional de La Plata. 


\section{Introducción}

La autobiografía es una manera de leer tanto como de escribir, confiesa Sylvia Molloy (Acto). ${ }^{1} \mathrm{Al}$ tiempo que despliega los protocolos de una lectura crítica, el enunciado de Molloy instala la pregunta acerca de los posibles rasgos que, presentes en un texto, habilitarían un modo de leer en clave autobiográfica. En otros términos, ¿cómo se organiza un modo de ver que permita leer en perspectiva autobiográfica textos que, tramados por fuera de las convenciones canónicas de la autobiografía, no invitan explícitamente a ser abordados en esa clave? ¿A partir de cuáles estrategias presentes en un texto es posible construir la autobiografía como un modo de lectura y qué significaciones expanden tales estrategias?

En el presente trabajo se intentará esbozar una matriz autobiográfica en la producción de Domingo Faustino Sarmiento, susceptible de ser puesta a funcionar como una máquina de leer un texto que juega en los bordes de la ley de la autobiografía: el texto en cuestión es Campaña en el Ejército Grande aliado de Sud América.

\section{Algunas cuestiones previas}

Julio Ramos (Desencuentros) ha señalado que, si bien a lo largo del proceso de la independencia las potenciales clases dirigentes

${ }^{1}$ Esta afirmación de Sylvia Molloy actualiza un momento de los debates teóricos en torno a la especificidad de la autobiografía. Hacia 1950 la reflexión sobre lo autobiográfico cobra un nuevo giro al dejarse definitivamente de lado la idea, inaugurada por Dilthey, de la autobiografía como la reconstrucción de una vida en el sentido de una forma de comprensión de los principios organizativos de la experiencia, de los modos de interpretación de la realidad histórica en que vive el autobiografiado. Las intervenciones de teóricos como Philippe Lejeune y Elizabeth Bruss pusieron definitivamente en crisis las nociones del texto como historia y del autor como propietario de la interpretación de la propia vida. Así, la instancia de la lectura apareció como una clave para la definición de la autobiografía. Según Bruss [1976], dado que la autobiografía adopta formas externas muy diferentes, es en última instancia la actitud del lector la que define un texto como autobiográfico. También para Lejeune [1975] el lector ocupa un papel central: la historia de la autobiografía es la historia de sus modos de lectura, sostiene. De esta manera, si en una primera etapa el estudio de la autobiografía encontraba una garantía en el valor objeti- 
latinoamericanas lograron un considerable consenso en la articulación de un "nosotros" que encontraba su punto de cohesión en la oposición contra España como enemigo común, la emergencia de los primeros gobiernos patrios puso de manifiesto las importantes contradicciones existentes en el seno de estas clases. La focalización en la necesidad de someter las particularidades a un proyecto homogeneizador que hiciese posible la construcción de los Estados nacionales no fue suficiente para reterritorializar la fragmentación interna que diluía la posibilidad de consolidación de los sujetos nacionales. La victoria contra España intensificó la atomización, en la medida en que las instituciones coloniales iban perdiendo su legitimidad y vigencia. De este modo, el conjunto de las prácticas sociales debieron enfrentarse a un vacío de autoridad cuyo corolario inmediato fue la puesta en crisis de los marcos institucionales que, en el orden anterior, les habían otorgado sus legalidades. En este contexto, durante la década de los veinte ${ }^{2}$ la práctica de la escritura aparece como respuesta "a la necesidad de superar la catástrofe, el vacío de discurso, la anulación de las estructuras, que las guerras habían causado" (Ramos 19).

Tras el período conocido habitualmente como "anarquía de los años veinte", se inició en Argentina una etapa donde el problema de la organización (constitucional) de la nación se instaló, de un modo más fuerte que anteriormente, como el eje organizador de los debates. Así, el Congreso Constituyente de 1824 sancionó, a instancias de Bernardino Rivadavia, una serie de leyes (la de Presidencia y la de Enfiteusis, entre las más significativas) a partir de las cuales ensayar la consolidación jurídica de un Estado. La labor del Congreso finalizó con la promulgación de la Constitución de 1826, un instrumento legal de corte unitario y debilitado por carecer de consenso. Debido a su falta de legitimidad - en gran parte como consecuencia de la política interior de Rivadavia - y a una política exterior cuyos desajustes quedaron en evidencia a partir de la independencia de la Banda Oriental, la Constitución de 1826

vo del texto, al problematizarse la identidad del autor la teoría se enfrentó a la multiplicidad e inasibilidad del yo autorial, trasladando el poder de garantía al sujeto lector.

2 La historiografía hispanoamericana ha establecido la batalla de Ayacucho (1824) como la finalización del periodo de la Independencia. 
quedó sin efecto. Se inauguraba de esta manera el denominado periodo de los pactos interprovinciales, ${ }^{3}$ una serie de convenios que, celebrados entre los caudillos, intentaron zanjar las diferencias con vistas al logro de la consolidación de un Estado. Tramados en las disputas generadas por los intereses personales y de clase que estos caudillos provinciales representaban, los pactos delimitaron un campo de problemas acerca de los cuales debía acordarse para que la organización nacional fuese posible. En estos términos, fueron dos las cuestiones que adquirieron un poder clasemático durante el periodo: la libre navegación de los ríos (punto en torno del cual se condensaban los grandes problemas económicos del momento) y el llamado a un Congreso General Constituyente (tema que aglutinó las discusiones político-institucionales).

Ahora bien, por debajo de la intención manifiesta de lograr la consolidación de un Estado central federal, estos pactos se constituyeron en una estrategia para tejer alianzas y dirimir las disputas entre los caudillos, al mismo tiempo que sirvieron a algunos de ellos para aglutinar poder alrededor de sus figuras. Evidentemente, quien mejor jugó sus cartas fue Juan Manuel de Rosas: valiéndose de la dinámica de los tratados entre provincias, el caudillo porteño logró crear las condiciones que lo convirtieron en el virtual gobernador de Buenos Aires. Fue así que, tras el fracaso de la revolución del general Lavalle, en 1829 Rosas accedió al gobierno de la Provincia de Buenos Aires, durante tres años e investido de facultades extraordinarias. ${ }^{4}$ Finalizado su primer mandato en 1832, y

3 “La caída del gobierno nacional de Rivadavia (1827) abrió un paréntesis de inestabilidad política en todo el país. Sucesos posteriores, como la sublevación de Lavalle contra el gobernador bonaerense Dorrego y la campaña del general Paz en las provincias interiores, llevaron a la Argentina al borde de una guerra civil. La firma de una serie de pactos interprovinciales determinaron la organización de dos bloques políticos enfrentados y dispuestos a la lucha armada. Unitarios en el interior y federales en el litoral - de acuerdo con las áreas donde impusieron respectivamente su dominio- pretendían para la Nación forzar sendas soluciones definitivas en el ámbito institucional. Junto con los nombres antes mencionados adquieren en estos momentos amplia notoriedad pública los de Juan Facundo Quiroga, Estanislao López y Juan Manuel de Rosas."(Weinberg 217)

4 En su primer gobierno (1829-1832) Rosas asume una función reforzada por una serie de atribuciones que excedían las habituales del Poder Ejecutivo provincial: las llamadas facultades extraordinarias, otorgadas para lograr una 
tras un breve interregno de tres años, Rosas volvió a la gobernación en 1835, esta vez con la suma del poder público y el ejercicio de las relaciones exteriores que todas las provincias de la Confederación Argentina delegaron en su persona.

Si la gestión de Bernardino Rivadavia significó la cristalización institucional del poder de la burguesía portuaria de Buenos Aires, con Rosas la provincia quedaba en manos de los intereses de cierta oligarquía terrateniente. El acceso al poder formal por parte de esta clase trajo consigo la implementación de una política económicoinstitucional que atentaba contra los intereses de las provincias del interior de la Confederación, política sostenida por medio del terror y la proscripción de todo atisbo de disidencia.

La permanencia de Rosas en el poder durante diecisiete años operó como un factor aglutinante de sus opositores. El caso paradigmático estuvo dado por los intelectuales de la denominada Generación de 1837, quienes se mantuvieron como un bloque considerablemente homogéneo en la oposición contra la política del dictador porteño. Se trataba de un grupo de jóvenes que, congregados inicialmente alrededor del Salón Literario fundado en Buenos Aires por el uruguayo Marcos Sastre, articularon una reflexión crítica sobre el tiempo que les tocó vivir. Como señala Nicolás Shumway (1991), los jóvenes del 37 "se asignaron dos altas tareas intelectuales: identificar sin idealización los problemas que enfrentaba el país, y trazar un programa que hiciera de la Argentina una nación moderna" (131). Con la emergencia de lo que puede considerarse como el primer grupo de intelectuales argentinos

[...] se inicia un ciclo que se prolonga hasta 1880 , año en que concluye el periodo del último de los tres primeros presidentes constitucionales de la nación unificada, cuya obra conjunta no fue sino la concreción de la política postulada por aquel movimiento inicial. (Zanetti, “Ensayo" 361)

mayor concentración de poder que le permitiera al nuevo gobernador solucionar la profunda crisis reinante. En su segundo gobierno (1835-1852) Rosas es investido con la suma del poder público, esto es, la reunión de los tres poderes (ejecutivo, legislativo y judicial) en cabeza del gobernador.

5 Los tres primeros presidentes de la nación unificada fueron Mitre, Sarmiento y Avellaneda. Cabe recordar que, luego de la sanción de la Consitución Nacional de 1853, con el establecimiento de la capital de la República, Buenos 
La afirmación precedente consigna la inclusión de Sarmiento -segundo presidente constitucional luego de la unificación nacional- dentro del perímetro de alcance de la Generación de 1837. En su San Juan natal, el joven Sarmiento simpatizó con la Sociedad Literaria, subsidiaria de la Asociación de Mayo de Esteban Echeverría y Juan Bautista Alberdi. Al igual que los porteños, los sanjuaninos se identificaban con los ideales de la Revolución de Mayo de 1810 y reflexionaban "sobre la hasta entonces ignorada realidad social argentina, discriminando lo político de lo social, según la visión que difundían las doctrinas sociológicas llegadas de Francia" (Zanetti, "Ensayo" 361).

Sarmiento participó del ambiente ideológico de los intelectuales del 37, pero su condición de hombre de provincia determinó una serie de particularidades respecto de los porteños que, si bien no presentaron inicialmente una zona de clivaje, pueden visualizarse como un telón de fondo que recorre su pensamiento y su obra. Su romanticismo

[...] es más espontáneo, más esencial, más demostrado en la acción que el de sus maestros porteños, preocupados por una línea de conducta -Echeverría en particular- que se amolde

Aires se sintió decapitada por la pérdida de la ciudad que era su centro de gravedad. Como resultado del enfrentamiento con el gobierno nacional, se produjo la secesión de Buenos Aires, que en 1854 se constituyó en un estado soberano. De todos modos, no hubo dentro de la provincia una posición unificada; la clase dirigente se dividió en dos grupos: autonomistas y nacionalistas. Los autonomistas, liderados por Alsina, consideraban que la secesión podía y debía mantenerse como una situación permanente; los nacionalistas, con Mitre a la cabeza, concebían la secesión como una circunstancia pasajera que debía ser superada mediante una reforma constitucional que garantizara la dirección de la república federal desde Buenos Aires. Enfrentados en la batalla de Cepeda (1859), Urquiza venció a Mitre, iniciándose de este modo el proceso que culminaría con la reincorporación de Buenos Aires en 1860 tras la proposición de ciertas reformas constitucionales que fueron aceptadas en la Asamblea Constituyente con el fin de lograr la pacificación. Una paz breve, ya que durante el gobierno de Derqui una serie de episodios sangrientos ocurridos en San Juan enfrentaron nuevamente a la Confederación con Buenos Aires, en su apoyo a los diferentes bandos sanjuaninos. En esta oportunidad hubo rebelión: el general Mitre, gobernador de Buenos Aires, levantó un ejército contra el presidente Derqui. Frente a los sucesos, Derqui designó comandante del 
a los principios de sus autores consagrados. Pero además, el romanticismo sarmientino proviene más de una convergencia con el contenido romántico que de una adhesión teórica a lo que podría considerarse las últimas novedades. La lectura hecha por Sarmiento de aquellos teóricos - Lerminier, Guizot, Cousin, Tocqueville y "el más alto metafísico de Europa", Pierre Leroux - produce en él un modo de captar la realidad histórica que también lo distancia, en particular de Echeverría y de Alberdi. La realidad histórica ha de estar vinculada a una idea de progreso continuo, cuyo objetivo parece darse en el propio transcurrir. Es el progreso que conlleva la historia humana por la misma dignidad del hombre. Así, este progreso se identifica en Sarmiento con el proceso histórico de aquí y de este momento: una concepción impensable en Echeverría o en Alberdi [...]. (Zanetti, “Ensayo" 361)

Hubo también en su escritura marcas de esta particularidad de Sarmiento. Si bien una característica de la generación romántica argentina fue la función de lucha otorgada a la escritura, se produjeron también una buena cantidad de textos (poesías, relatos, novelas) donde las preocupaciones políticas ingresaron de una manera más oblicua. Por el contrario, se hace difícil encontrar en la producción de Sarmiento escritos en los que la intención militante se debilite. Otro rasgo que singulariza sus textos en la masa de las

ejército nacional a Urquiza, por entonces gobernador de Entre Ríos. De esta manera, Mitre y Urquiza volvían a enfrentarse pero bajo condiciones políticas muy diferentes. El federalismo tradicional carecía de unidad por el resentimiento que causaba la influencia de Urquiza, incluso en el propio presidente Derqui. En esta situación, Urquiza fue a la guerra desconfiando de sus propios adeptos y convencido de que no habría verdadera paz sin un acuerdo de fondo con Buenos Aires. Vencido por Mitre en la batalla de Pavón (1861), Urquiza abandonó a Derqui y volvió a Entre Ríos; como consecuencia, se dispersó el ejército confederado, el presidente se fugó y se disolvieron los poderes nacionales. Convencido de que era preferible salvar el orden constitucional a seguir luchando por la hegemonía, Urquiza pacta con Mitre: el porteño se comprometía a la defensa de la Constitución y a respetar al entrerriano como gobernador de su provincia; por su parte, Urquiza se hacía a un lado para que Mitre subordinara a las provincias federales del interior y restableciera la federación organizándola desde Buenos Aires. El acuerdo logró conciliar el ordenamiento federativo con las demandas, ahora atemperadas, de los porteños. Bajo estas condiciones Mitre llegó a la primera magistratura. 
escrituras contemporáneas es el permanente cruce de modalidades de carácter autobiográfico. ${ }^{6}$ Parece entonces pertinente pensar que estas dos peculiaridades - militancia y autobiografía - tejen las textualidades sarmientinas delineando un proyecto creador (Bourdieu) que se imagina para suturar hiatos: texto y acción política se sobreimprimen porque lo que los define es la trama de una subjetividad que los hace posibles. ${ }^{7}$

Sarmiento fue pobre, provinciano y autodidacta. Estas condiciones personales lo distanciaron del resto de su generación, al tiempo que delinearon la figura que presentó en su vida pública. Esta construcción de imagen ${ }^{8}$ no sólo determinó el modo en que fue visto por sus contemporáneos, sino que también persistió a lo largo del siglo $X X$ en el pensamiento de intelectuales prestigiosos "como un modelo ya inalcanzable [...]. Pensamos simplemente en Lugones, Martínez Estrada y aun en Viñas" (Zanetti, "Ensayo" 361). Y tal vez sea así porque, en Sarmiento, la construcción de imagen y el proyecto creador se acercan hasta sobreimprimirse, se alcanzan hasta fundirse.

6 Como se verá oportunamente, la autobiografía fue uno de los modos dominantes en la narrativa argentina del siglo XIX. Lo que marca una peculiaridad en la producción sarmientina es que las modalidades autobiográficas aparecen en todos los textos que componen su obra.

7 Paul John Eakin concibe el acto autobiográfico como un modo de autoinvención que se practica primero en la vida y se formaliza en la escritura (Eakin 1985)

8 Me refiero a "construcción de imagen" en el sentido de los planteos de María Teresa Gramuglio [1992]. En su artículo "La construcción de la imagen", presenta una serie de preocupaciones en relación con las imágenes de escritor que, con frecuencia, los propios autores construyen en sus textos. Se trata de un problema de historia literaria y no de poética, advierte Gramuglio. Estas construcciones - que por su fluidez y falta de cristalización pueden pensarse en términos cercanos a las estructuras de sentimiento de Raymond Williams - convocan un conglomerado de motivos heterogéneos que invitan a leer una serie de cuestiones: cómo el escritor representa, en lo imaginario, la constitución de su subjetividad en cuanto escritor; cuál cree que es su lugar en la literatura y en la sociedad. Esta clave de lectura se habilita, de acuerdo con las hipótesis de Gramuglio, porque "la construcción de la imagen conjuga una ideología literaria y una ética de la escritura" (39). En la articulación de estas figuras con frecuencia se traman motivos que han llegado a convertirse en verdaderos temas. Pero, "estas construcciones están de tal modo atravesadas por la historia, que dichos motivos, aunque recurrentes, nunca resultan idénticos, y siempre se reformulan y resemantizan en función del contexto en el que se inscriben" (39). Así, las figuras de escritor remiten, por un lado, a la constitu- 


\section{Modalidades autobiográficas en Campaña en el Ejército Grande}

Tras la batalla de Caseros, a fines de febrero de 1852, Sarmiento se alejó de Buenos Aires al advertir que, en el nuevo periodo que se iniciaba con la caída de Rosas, su colaboración con el general Urquiza resultaría imposible. Bajo estas circunstancias e instalado transitoriamente en Brasil, Sarmiento comenzó a escribir lo que sería su Campaña en el Ejército Grande aliado de Sud América. Publicó en Río de Janeiro la primera parte del texto, "una escueta transcripción de documentos justificativos de su conducta y acusatorios de la de Urquiza" (Halperín Donghi, "Prólogo" 43), bajo el título de Ad Memorandum. Un prólogo y una carta a Bartolomé Mitre aparecieron en El Nacional, de Buenos Aires, ${ }^{9}$ constituyendo la segunda entrega.

ción de una subjetividad fechada; y por otro, al estado del campo literario al cual el escritor se integra, a los conflictos del campo, a las formas posibles de acceso y al conjunto de condiciones que regulan la práctica literaria. Es en este sentido que las imágenes de escritor se conforman como ideologemas, como unidades discursivas que imaginan soluciones simbólicas para conflictos históricos determinados. Ahora bien, el motivo de la construcción de imágenes de escritor se convierte en recurrente bajo circunstancias históricas precisas, esto es, a partir de la autonomización de los campos literarios en las literaturas nacionales. Dado que la emergencia de un campo literario como autónomo no admite ser fechada de manera puntual, será necesario pensar en un proceso de formación y consolidación de las condiciones que posibilitaron que el espacio cultural tomara cierta autonomía respecto del poder eclesiástico y político, y que en ese dominio el campo literario adquiriera una especificidad más o menos precisa; también haría falta que el ser escritor y el escribir literatura fueran investidos mediante una significación y una valoración que distinga la literatura de otras prácticas escriturarias. En la Argentina del siglo XIX, la actividad intelectual aparece casi totalmente heterónoma, y la escritura se reviste de instrumentalidad respecto de la actividad política. Será recién en el período que se inaugura aproximadamente en torno al Centenario que podrá reconocerse un proceso que, por medio de la creación de redes discursivas e institucionales específicas, posibilitará la emergencia del primer campo literario autonomizado en Argentina.

Tomando en consideración esta constelación de problemas, en el presente trabajo se considerará que la construcción de imagen llevada a cabo por Sarmiento en sus textos, si bien verifica operaciones para cuya lectura resultan de suma productividad las hipótesis de Gramuglio, no se trata de una figura de escritor sino de la imagen del letrado.

9 La carta a Mitre ya había sido publicada en Brasil. 
De regreso a su país natal, Sarmiento fue detenido y acusado de conspiración, y pese a ser absuelto, se exilió por segunda vez en Chile. Alentado por el fracaso de Urquiza - que significó la secesión de Buenos Aires - publicó "la tercera entrega de Campaña, en la que el cuerpo narrativo de la obra iba precedido de una carta dedicatoria a Alberdi, que Sarmiento - poco ducho en el arte de insinuar pérfidamente- llenó de lo que él creía alusiones escondidas, y eran injurias muy directas al destinatario de la dedicatoria" (Halperín Donghi, "Prólogo" 43). Se hace así evidente que la constelación de textualidades que Sarmiento escribió, editó y reunió para dar forma a Campaña en el Ejército Grande constituyeron un artefacto vinculado directamente con su intención de argumentar acerca de la imposibilidad de colaborar con Urquiza. Para ello narró "su tentativa de cooperar con el caudillo entrerriano y los miserables resultados obtenidos en ella" (Halperín Donghi, "Prólogo" 44) apelando a modos propios de la autofiguración en la narrativa argentina del siglo XIX.

\section{Los géneros del yo en la literatura argentina del siglo XIX}

El relato de la propia vida marca una línea que atraviesa la narrativa argentina a lo largo del siglo XIX. Como modo de afirmar el nombre propio, a partir de las guerras de la independencia comenzaron a proliferar los textos autofigurativos de un nutrido grupo de personajes notables. Memorias, narraciones de viajeros, diarios de distinta índole, autobiografías, trazaron la historia de la élite del poder en la Argentina del XIX (Prieto 22). Esta modalidad, ausente en las escrituras coloniales, 10 emergió cuando, con la Revolución de Mayo, "un nuevo modelo de funcionamiento social empieza a abrirse paso: el del liberalismo, modelo que terminará por imponerse con la unificación nacional en el ochenta" (Stratta 481).

En efecto, la imaginación liberal instaló la concepción del individuo como artífice posible de la construcción del propio nombre a partir de las condiciones y méritos personales. La colocación social

10 En su trabajo sobre la autobiografía hispanoamericana, Sylvia Molloy postula que, si bien los relatos en primera persona abundaron en el periodo colonial y pueden considerarse como antecedentes remotos de la escritura autobiográfica - piensa en textos tales como los Comentarios reales, del Inca Garcilaso; la "Respuesta a Sor Filotea de la Cruz", de Sor Juana; las confesiones ante 
del individuo no dependería ya de las prerrogativas adquiridas por el nacimiento - o de su carencia-, sino de las propias aptitudes y valores. Así, en el contexto de este nuevo imaginario, la exhibición de lo personal adquirió un nuevo sentido que delinearía la forma de la narración autobiográfica. Hablar de sí mismo, narrar la propia vida se constituyó en un modo de autovalidación con "pretensiones a la historicidad, a la utilidad pública, a los vínculos del grupo, al testimonio" (Molloy, Acto 21). De este modo, la autofiguración vino a presentar subjetividades que, frente al vacío institucional que dificultaba sus configuraciones, se valieron de una serie de estrategias que permitieran ligar el yo a la comunidad.

Como sostiene Sylvia Molloy (Acto), el siglo XIX hispanoamericano asistió a una singular toma de conciencia de sujeto y cultura, resultante de una crisis ideológica producida por la Ilustración europea y por la independencia de España. El pasaje de un orden abolido a otro aún no consolidado trajo consigo una crisis de autoridad que abrió el espacio para las preguntas en torno de las identidades y culturas nacionales, disparándose una serie de debates donde se renegociaron las relaciones con España y, de un modo más general, con Europa. Así, si durante la Colonia las escrituras del yo encontraron su legitimidad en un Otro institucional que organizaba el campo posible de la alocución, una vez desaparecida esta legalidad institucional irrumpió la pregunta que vendría a regir la escritura autobiográfica:

Si ya no se escribe para el Rey ni para la Iglesia, ¿para quién se escribe? ¿Para la verdad? ¿Para la posteridad? ¿Para la historia, disciplina que muchos autobiógrafos convertirán en fuente de validación? A esta crisis de autoridad corresponde un yo en crisis que escribe en un vacío interlocutorio. Las dificultades del autobiógrafo hispanoamericano, las vacilantes figuraciones a las que recurre,

el tribunal de la Inquisición-, se trata de textos cuya "finalidad primaria no es autobiográfica, aun cuando la autobiografía constituya uno de sus logros involuntarios." (Acto 13.) Señala la autora que: "El hecho de que los textos mencionados se destinaran, ante todo, a un lector privilegiado (el Rey de España, el obispo de Puebla, el tribunal eclesiástico) que ejercía poder sobre el escritor y su texto; el hecho de que la autonarración fuera menos un propósito que un medio para lograr ese propósito; y, por último, el hecho de que rara vez haya crisis en esta escritura del yo (o rara vez haya un yo en crisis), hacen que el resultado sea sólo tangencialmente autobiográfico" (Acto 13) 
el constante afán por conquistar el aprecio de los lectores, configuran un modelo ambiguo que siempre apunta a la misma pregunta, sin formularla abiertamente: “¿Para quién soy yo un 'yo'? o, mejor dicho, "¿para quién escribo 'yo'?" La vacilación entre persona pública y yo privado, entre honor y vanidad, entre sujeto y patria, entre evocación lírica y registro de los hechos, son sólo algunas de las manifestaciones de la vacilación que caracterizó (y acaso sigue caracterizando) la escritura autobiográfica en Hispanoamérica. (Molloy, Acto 14-15; las cursivas son mías)

Este sujeto vacilante se inscribe ya en los primeros textos autobiográficos argentinos a través de un motivo que va a ser predominante en el desarrollo del género a lo largo del siglo XIX. En la mayoría de los casos, la justificación de la propia actuación política o militar en el nuevo periodo va a articular una línea de significaciones presentes en los textos. La vacilación llevó al sujeto a la justificación de sus actos públicos, a la vez que instalaba el relato de la propia vida en una zona donde literatura y política se intersectan: este cruce dejó su marca en la textualidad mediante la composición del yo que intentaba autovalidarse. Los autobiógrafos del XIX compusieron sus figuras textuales por medio de la selección de los motivos narrativos que encontraban en sus propias vidas, de acuerdo con las imágenes que tenían de sí mismos y conforme los valores sociales dominantes. ${ }^{11}$ De esta manera, la literatura de introspección dio forma a un conjunto de héroes literarios que sintetizaban en sus configuraciones determinados rasgos de época.

Los autobiógrafos y memorialistas del periodo de la Independencia, inmersos en un complejo contradictorio proceso, "abordaron la escritura como práctica que, entre otras cosas, les permitía esclarecer su propia actuación y dejar a salvo su buen nombre" (Stratta 483). Este modo de acercarse a la escritura hizo explícitos los motivos que caracterizarían el desarrollo de los géneros del yo a lo largo del siglo XIX: la vida personal como modelo y el buen nombre sostenido en el valor de la actuación personal. Los sujetos narraban la vida pública, y las mínimas referencias al ámbito pri-

11 Cfr. Stratta 481. Adolfo Prieto (21) argumenta en un sentido similar, a partir de las hipótesis teóricas de Georg Misch (El problema). Siguiendo de cerca los desarrollos de Bergson y Cassirer, Misch define la autobiografía como el testimonio del grado de conciencia de sí mismo que el individuo tiene en cada etapa de su vida. 
vado tuvieron "el sentido de una demostración de la calidad individual del hombre público" (Stratta 484). Así los textos presentaban un héroe cívico, la imagen del buen ciudadano. Las memorias escritas durante las guerras civiles inmediatamente posteriores a la Independencia tradujeron en clave militar las imágenes de sus héroes, destacando los valores del militar disciplinado - opuestos a la indisciplina de los caudillos-, hegemonizando los textos el modelo del soldado moderno, esto es, del militar de carrera.

Los intelectuales de 1837 condensaron en el ideologema civilización frente a barbarie su versión de las disputas que escindían a la Confederación Argentina. Fue esta formulación ideológica la que trazó el dibujo del héroe que los textos introspectivos mostraron: el modelo del "hombre civilizado":

Los intelectuales del 37 sintieron que ellos mismos encarnaban los valores que levantaban como bandera y, por lo tanto, mostrar la propia vida fue para ellos proporcionar el ejemplo de una vida civilizada. El nuevo héroe literario es el hombre educado, el individuo que se procura una formación intelectual y política, el viajero que busca en países más adelantados prototipos de ideas e instituciones progresistas. (Stratta 487)

Tales textos operaron anclando la vocación ejemplificadora del género y a partir de allí comenzaría a imprimirse un viraje que, hacia 1880, ya encaminada la organización nacional de acuerdo con el esquema liberal, culminaría con la redefinición de lo autobiográfico. A partir del ochenta, la autofiguración deja de ser un espacio de articulación de modelos para convertirse en un lugar donde tiene cabida la diferencia, la particularidad, la especificidad de un sector social determinado. Los autobiógrafos del ochenta, vinculados de manera mediata al poder político y económico, se imaginaron a sí mismos como los actores de una vida social distinguida:

La anécdota, modo típico de la charla social, y la cita, que remite a las lecturas hechas en idioma extranjero, son los recursos que utilizarán para la mostración de sus vidas, y el modelo del hombre de mundo que reúne en sí mismo todas las posibilidades será el denominador común de esta época en la que la autobiografía ocupa un lugar dominante en el panorama literario. (Stratta 482)

Es notorio, entonces, que las estrategias de autofiguración permiten visualizar cómo "al diversificar la política sus prácticas dis- 
cursivas, la literatura hace otro tanto y, por supuesto, también la autobiografía" (Molloy, Acto 15). El yo habla desde diferentes lugares, poniendo en escritura diferentes preocupaciones que resuenan en el texto "como escena de crisis, siempre renovada, necesaria para la retórica de la autofiguración en Hispanoamérica" (15), una retórica que al llegar el siglo XX continuará "moldeando el discurso de la autorrepresentación en Hispanoamérica, pues ha llegado a ser elemento intrínseco de la autopercepción de sujeto" (21).

\section{Lo autobiográfico en Sarmiento}

Probablemente sea posible leer en la escritura autobiográfica de Sarmiento la puesta en escena de un conjunto de estrategias a partir de las cuales construir una máquina de leer en esa clave textos de su producción que no responden de manera estricta a las formas de la autobiografía. Y tal vez sea Recuerdos de provincia una superficie adecuada para un ensayo en ese sentido, para intentar aprehender esa forma que recorre la producción de Sarmiento zurciendo incluso los materiales heterogéneos que conforman la hibridez transdiscursiva de sus textos.

Isabel Stratta (491) puntualiza cómo Sarmiento, al reseñar sus escritos al final de Recuerdos de provincia, incluye este texto autobiográfico en el marco del sistema literario de la biografía. Para Sarmiento "la biografía es el libro más original que puede dar la América del Sur en nuestra época, y el mejor material que haya de suministrarse a la historia" (Sarmiento, Recuerdos 144). De esta manera, el género biográfico (con la autobiografía considerada como una de sus especies) es despojado de las vacilaciones que lo atraviesan. ${ }^{12}$ Sarmiento atribuye Recuerdos de provincia al mismo género que Facundo, y asume el texto como su propia "biografía". Pero, como advierte Sylvia Molloy, a diferencia de Facundo - cuya autoridad, sostiene Sarmiento, deriva de documentos anteriores-, Recuerdos de provincia no convoca ningún documento en el que descanse su garantía de verdad:

12 “El autobiógrafo varón del siglo XIX escribe un texto vacilante entre la historia y la ficción, pero en el momento de clasificarlo prefiere evitar la ambigüedad. En beneficio de sus lectores y de su propia autoestima, lo coloca dentro de los límites, más respetables, del primer género; la autobiografía decimonónica se legitima como historia, y como historia, se justifica por su valor documental"' (Molloy, Acto 187). 
No hay registro previo para el yo, salvo el texto no escrito de la propia memoria, y el único acto de escritura que lo sostiene es el que él mismo efectúa en el proyecto autobiográfico. [...] con un deliberado esfuerzo por ser coherente que es tan ingenuo como revelador, arma un tinglado para su relato de vida que le permita tratarlo como si fuera una biografía. Para adecuarse a esta exigencia, y acaso también para evitar acusaciones de egocentrismo, Sarmiento inventa una cadena de documentos para su yo. (Molloy, Acto 193)

El documento sobre el que puede fundar la historia de su yo son las calumnias que sobre él escriben sus enemigos, y dando "valor documental a las críticas que publica contra él la prensa argentina, Sarmiento es fiel al esquema que inauguró en Facundo: recurre a un documento previo para certificar su proyecto" (Molloy, Acto 194).

$\mathrm{Al}$ asimilar la narración autofigurativa al género biografía, Sarmiento "asigna a ambos el mismo valor ejemplar" (Stratta 491). Se trata de una ejemplaridad que excede la didaxis para transformarse en la matriz narrativa que otorgará al texto su carácter modélico respecto del género en el siglo XIX argentino. Afirmación del nombre propio, identificación de la historia personal con la del país, utilidad de la vida individual como modelo: rasgos característicos que, con mayor o menor grado de explicitación están presentes en toda la escritura autobiográfica argentina del siglo XIX.

En un trabajo ya canónico, Carlos Altamirano y Beatriz Sarlo afirmaron, en relación con Recuerdos de provincia, que la polémica antirrosista se revela como el pretexto de una operación más compleja. Para los autores, el texto de Sarmiento se inserta en la coyuntura que precede y sucede inmediatamente a la caída del rosismo: se trata de un momento de propuestas para la organización nacional. Sarmiento se propone "convocar la atención sobre quien constituye la verdadera alternativa" (Altamirano, "Vida ejemplar" 17), como operación previa al planteo de una nueva trama de alianzas posibles, podría agregarse. En los recuerdos sarmientinos, Altamirano y Sarlo leen un primer momento del reacomodamiento del campo ideológico que comienza a hacerse visible tras el derrocamiento de Rosas: Sarmiento no sólo constituye una alternativa frente a Rosas, sino también frente al régimen de los caudillos. Pero además se verifica en el texto autobiográfico un pliegue político más: 
Sarmiento busca definir por adelantado el papel que en la Argentina posrosista deben desempeñar los actores que, en el presente, las necesidades de alianza colocan lado a lado. En particular los papeles respectivos del reformador letrado y del caudillo. (Altamirano, "Vida ejemplar" 17)

La definición del letrado - el hombre de letras ligado de un modo más o menos funcional a las estructuras del poder político para el sostenimiento y la reproducción de sus aparatos ideológicoculturales - como figura opuesta al intelectual - que articula su práctica definiéndola como crítica frente a los constructos ideológicos sustentados desde las instituciones formales $-{ }^{13}$ se ha convertido en un lugar común en los estudios latinoamericanistas. Ahora bien, la figura de Sarmiento parecería desbordar ambas categorías al inscribirse en un campo de problemas que se particulariza en términos de una coyuntura específica. Para el escritor, lo difícil fue cómo articular una imagen y una práctica que sostuvieran la enunciación de un proyecto estatal instalando al sujeto en el lugar de la única alternativa viable, como quieren Altamirano y Sarlo. Entonces, no se asimila ni a la figura del letrado ni a la del intelectual, sino que se coloca en un lugar intersticial que, tomando elementos de una y otra categoría, se erige en un espacio más complejo. Sarmiento buscó articular la crítica del presente tramándola con un proyecto estatal: dos superficies discursivas que tejen el texto creador de una imagen que se legitima por medio de su propia construcción, esto es, en la escritura. Se pone así en escena un lugar de enunciación que imagina su emisor hablando estas hablas: hablando, en definitiva, de sí mismo; un enunciador que habla de sí mismo en la lengua que construye la escena, a la manera del diario íntimo, la carta, la literatura autofigurativa y de introspección. Se recorta de este modo una narratividad autobiográfica que recorre la serie de los textos de Sarmiento, y que quizás pueda pensarse como la matriz (o una de las matrices) que viene a homogeneizar lo heterogéneo del corpus sarmientino.

Por el modo en que, en el marco de un proyecto de Estado, define los espacios de funcionalidad de los futuros letrados (esto es, define

13 En el campo latinoamericano, un buen ejemplo de la aparición de ambas construcciones en momentos sucesivos del discurso de una misma subjetividad lo ofrece la figura de Sor Juana. Reformadora letrada funcional al proyecto colonial de la Corona, se transforma en una intelectual crítica que termina enfrentada al Santo Oficio. 
desde el espectro ideológico del 37 la colocación y función de los intelectuales de la Generación de 1880), la construcción del enunciador hace pensar en que no fue el lugar del reformador letrado el que Sarmiento reclamaba para sí, sino la posición de quien se arroga la capacidad de definir esa figura futura. Y así delineó su propia imagen exhibiéndola en la comodidad con que se instala en el proyecto estatal que imagina como viable: se concreta una figura que condensa un verosímil que viene a sostener el relato. Así se expande una lógica discursiva que organiza sus convenciones, mediante la puesta en forma de una fábula que narra la historia de quien es la única garantía para la concreción de un proyecto estatal sólido, una historia que organiza a partir de la dicotomía entre civilización y barbarie la imagen del "hombre civilizado" que se define por oposición frente a la barbarie del caudillo. De tal modo, este enunciador es la figura que se instala como el significante de un ideologema, esto es, de otro significante. $\mathrm{Y}$ el sujeto es siempre un significante para otro significante, sabemos desde Lacan.

Es así como, para el Sarmiento de esta etapa, se puede pensar en la formulación de una categoría particular, la de un sujeto que se sitúa como fuente de un proyecto que imagina un relato verosímil, el cual articula la figura del reformador letrado en la crítica de un presente que se narra como la barbarie de los caudillos. Y para otorgar espesor a la subjetividad que postula, necesariamente expande una narratividad autobiográfica que se ofrece como una herramienta crítica para indagar textos tales como Campaña en el Ejército Grande aliado de Sud América.

\section{Campaña en el Ejército Grande aliado de Sud América}

A partir de la caída de Rosas, tras la batalla de Caseros (3 de febrero de 1852), el polo opositor comenzó a manifestar progresivamente las fisuras que llevaron a su disolución. En este sentido, puede uno estar de acuerdo con Nicolás Shumway (1995) en que la caída de Rosas posibilitó la emergencia y visibilidad de las diferentes ficciones orientadoras ${ }^{14}$ que, alojadas en el seno del bloque antirro-

14 Shumway llama ficciones orientadoras al conjunto de relatos que articulan el imaginario político de una nación, una serie de narraciones "necesarias para darle a los individuos un sentimiento de nación, comunidad, identidad colectiva y un destino común nacional"(13). 
sista, permanecieron silenciadas como modo de otorgar cohesión a la lucha contra el gobierno de Buenos Aires. Alejado Rosas del poder, los diferentes modos de pensar la nación tomaron cuerpo reorganizándose así el mapa ideológico de la Confederación Argentina. La manifestación más evidente de este nuevo estado de cosas estuvo dada por la polémica sostenida entre Sarmiento y Juan Bautista Alberdi, "debate que toca puntos de importancia fundamental en las ficciones orientadoras de la Argentina" (Shumway 188). ${ }^{15}$

Campaña en el Ejército Grande aliado de Sud América fue el "intento más directo de Sarmiento de comprometer a Alberdi en un debate, y su ataque más virulento contra Urquiza" (Shumway 198). Existe una evidente dificultad para establecer con exactitud la fecha de su publicación, dado que, con semanas de diferencia, fueron divulgados en Río de Janeiro, Santiago de Chile y Buenos Aires textos que habrían de integrar el cuerpo de Campaña:

15 A pesar de haber actuado contra Rosas junto a sus compañeros del 37, el sector más purista de los unitarios siempre se mantuvo cauto respecto de Juan Bautista Alberdi, viéndolo con contemplaciones frente a los caudillos. En un texto de 1837, Fragmento preliminar al estudio del derecho, Alberdi "afirmaba que Rosas estaba destinado a jugar un papel histórico en el desarrollo de una Argentina orgánica, ya que el dictador con todos sus defectos representaba una transición necesaria entre una nación informe y primitiva y una moderna república democrática" (Shumway 196). Y en La República Argentina., 37 años después de su Revolución de Mayo (1847), postulaba como necesaria la no exclusión de los caudillos de la operación argentina. Pese al manto de sospecha que recaía sobre Alberdi, Sarmiento consideró axial sumarlo al proyecto antirrosista. Si bien Sarmiento y Alberdi habían mantenido diferencias, "antes del conflicto Urquiza-Mitre sus desacuerdos habían sido más académicos que prácticos" (Shumway 196). Pero hacia mediados de 1852, al volver Sarmiento de Chile (donde Alberdi permaneció durante la campaña de Urquiza contra el dictador porteño), la disputa adquirió resonancias políticas reales, fundamentalmente en lo concerniente a "la existencia de un gobierno secesionista en Buenos Aires que necesitaba legitimación ideológica"(Shumway 196).

En su afán por mantener a Alberdi alejado del gobierno de Urquiza, Sarmiento se pronunció por el elogio de las Bases, a lo cual Alberdi correspondió mediante el envío de ejemplares de su libro al congreso constituyente de Santa Fe. Se inicia de este modo el intercambio epistolar donde "Sarmiento trató de volver a Alberdi contra Urquiza, mientras Alberdi recomendaba espíritu práctico y paciencia, con la esperanza de mantener atemperado el famoso carácter de Sarmiento" (Shumway 196). El 16 de agosto de 1852 Alberdi y un grupo de adherentes a Urquiza se convocaron para formar el Club Constitucional de Valparaíso, cuyo objeto fue la oficialización de su apoyo al entre- 
La primera parte apareció en Río en 1852, poco después del fin de la campaña. Secciones adicionales aparecieron casi simultáneamente en periódicos de Santiago de Chile y Buenos Aires durante diciembre del mismo año. El volumen contenido en las Obras completas incluye cartas y artículos pertinentes al periodo que no aparecieron en la versión de 1852. Como resultado, no sólo la fecha de publicación es imposible de afirmar; tampoco hay un texto "original". (Shumway 198 nota 1)

rriano. "Furioso con Alberdi, Sarmiento no tardó en organizar su propio club, el Club de Santiago, para apoyar a Buenos Aires y los mitristas. Sus miembros eran en su mayoría viejos exiliados porteños demasiado débiles para volver a Buenos Aires" (Shumway 197]). Alberdi catalogó al club de Sarmiento como un grupo de "momias respetables", frente a lo cual un Sarmiento indignado redactó un grupo de tres textos panfletarios (la llamada "Carta de Yungay" dirigida a Urquiza -1o. de octubre de 1852-, un artículo periodístico en el que examina el Acuerdo de San Nicolás - 26 de octubre de 1852- y un prospecto acerca del aporte de los sanjuaninos al proceso nacional), textos publicados en periódicos chilenos pero en los cuales se recorta un lector privilegiado: Alberdi. En realidad, la gestión más directa de Sarmiento para involucrar a Alberdi en un debate y los más cáusticos embates contra Urquiza aparecen en Campaña en el ejército grande. En la carta-dedicatoria, Sarmiento establece las diferentes posiciones ocupadas por cada uno para impugnar la verdad de los dichos de Alberdi: "[...] En la prensa y en la guerra V. sabe en qué filas se me ha de encontrar siempre, y hace bien en llamarme el amigo de Buenos Aires, a mí que apenas conocí sus calles, V. que se crió allí, fue educado en sus aulas, y vivió relacionado con toda la juventud. [...] Háblole de prensa y de guerra porque las palabras que se lanzan en la primera se hacen redondas al cruzar la atmósfera y las reciben en los campos de batalla otros que los que las dijeron" (Sarmiento Campaña 118-119). En el "Epílogo", deja sentada la intención de su relato: "[...] mostrar el origen de las ideas que en diversos escritos he emitido, contra la utilidad, justicia y necesidad de levantar de nuevo al general Urquiza. He querido sobre todo disipar las perversas preocupaciones que hombres mal informados por favorecer a Urquiza amontonan contra Buenos Aires, por un acto que no es suyo sino del ejército de Urquiza, y que éste provocó e hizo necesario y aceptable por su ineptitud y sus desmanes. Pueden llamarme ahora detractor, los que reciben inspiraciones del Paraná; pueden suponerme apasionado. ¿Apasionado de qué?" (Sarmiento, Campaña 305).

Alberdi respondió a Sarmiento dirigiéndole, entre enero y febrero de 1853, cuatro extensas cartas abiertas. Las "Cartas sobre la prensa y la política militante de la República Argentina", conocidas habitualmente como Cartas quillotanas, marcan un viraje en el pensamiento alberdiano: en ellas se distancia "del elitismo de la Generación del 37 y se acerca a posiciones de cuño nacionalista, provincianista y, hasta se podría decir, populista. De modo que 
El artefacto que conocemos como Campaña en el Ejército Grande se presenta como un relato de la empresa de Urquiza contra Rosas construido a partir de tres fuentes principales. En primer lugar, los boletines de guerra que, para ser distribuidos entre los soldados, Sarmiento publicaba en su marcha junto al ejército. En segundo término, las cartas y diarios personales que narran sus desinteligencias con Urquiza, textos muchas veces contradictorios de la versión

es posible ver las Cartas como un regreso a intereses que Alberdi enunció ya en el Fragmento de 1837, donde había mostrado una visión mucho más pragmática de Rosas" (Shumway 202). A través de esta inflexión, Alberdi identificó un nuevo enemigo en el liberalismo de los viejos unitarios y de los mitristas, desaprobando su tendencia al cambio y al desconocimiento de la tradición. Puntualmente embate contra "la retórica inflamada de Sarmiento y Mitre, no porque esté en desacuerdo con sus principios confesos, sino porque usan estos principios para enmascarar la ambición personal" (Shumway 202-203). Para Alberdi, los liberales utilizaron la prensa y la guerra como modo de aniquilar el ser propio de la población gaucha y de los caudillos, sus representantes naturales. Así, Alberdi insinúa su visión del gaucho como elemento vital de la identidad nacional y de la necesidad de que los caudillos asumieran un rol dentro del incipiente sistema constitucional. Es notable, en este sentido, el corrimiento de Alberdi respecto de sus posiciones en las Bases donde condenaba a los nativos mestizos asumiendo una postura inmigracionista. En el nuevo sistema que Alberdi expone, con su reconocimiento de la especificidad argentina respecto de los modelos extranjeros donde Sarmiento, entre otros, ponía su mirada, "afirma que la población peculiar de la Argentina (los gauchos), su gobierno (los caudillos) y su herencia (la España colonial) eran los únicos puntos de partida posibles para construir un país" (Shumway 204).

Pero el eje de las Cartas lo constituye la indagación del lugar ocupado por el periodismo en el proceso político argentino. Su visión del problema se condensa en su reiterada acusación a Sarmiento y Mitre de ser "caudillos de la prensa": sus modalidades periodísticas sublevan a la población, haciéndole creer que es posible desarticular la autoridad de los caudillos y que la mera destrucción de uno u otro jefe posibilitará la república representativa. Rearticulando en el debate el ideologema civilización contra barbarie, Alberdi categoriza el ejercicio periodístico de Mitre y Sarmiento como una prensa de vandalismo, mentira e ignorancia. En una invectiva en la que quizá puede leerse un reclamo de autonomía de las tareas intelectuales en relación con el campo de lo político, Alberdi identificó a Sarmiento y Mitre como políticos que ejercían la escritura como estrategia de autopromoción que, además, involucraba la fundación y dirección de órganos de prensa. También, en este sentido, Alberdi lee Recuerdos de provincia de Sarmiento como la construcción de un nombre como campaña política. Impugna, además, la Campaña en el ejército grande sosteniendo que se trata de una "historia sin documentos". 
oficial que aparecía en los boletines. ${ }^{16}$ Por último, se insertan en el libro nuevos materiales que Sarmiento agrega en Chile y que en su mayoría se trata de invectivas contra el caudillo entrerriano. Mediante la edición y el montaje de estos materiales heterogéneos, Sarmiento compone una textualidad compleja que, expandiendo los sentidos alojados en las grietas del relato del triunfo contra Rosas, configura una nueva cartografía para un nuevo periodo.

El aparato enunciativo de Campaña en el Ejército Grande pone en escena el quiebre ideológico operado entre los intelectuales antirrosistas tras la batalla de Caseros. En este texto se articula un sistema formal de enunciación que, diseminando el campo de la interlocución, redistribuye los bienes elocutivos. A diferencia de escritos anteriores (Facundo, Recuerdos de provincia) en los que aparecía un destinatario implícito susceptible de objetivarse en la figura de Rosas, la Campaña en el Ejército Grande fragmenta el espacio de la alocución. Pero la fragmentación de la interlocución no sólo pone en escena la fractura del campo antirrosista: también configura una estrategia en términos de la construcción de un yo con una autoridad suficiente que sostenga la propuesta del proyecto sarmientino. Si Facundo legitima su autoridad en documentos previos y Recuerdos de provincia inventa una cadena de documentos para su yo de acuerdo con las leyes de la biografía, Campaña en el Ejército Grande se presenta como un conjunto de textos que, sometidos a procedimientos de edición, fragmentación y montaje, se articulan en la invención de un yo. A través de la inscripción de interlocutores diferentes y diferenciados, Campaña en el Ejército Grande exhibe en diversos niveles textuales un conjunto de situaciones de enunciación que, por contigüidad, trazan un sistema de legitimidad para el sujeto que (se) escribe. Esta estrategia, puede pensarse, opera básicamente en dos planos: el diseño de los destinatarios de las cartas y los relatos que, insertos en distintos marcos genéricos, narran situaciones comunicativas.

Sarmiento respondió a las arremetidas de las Cartas quillotanas en una serie de cartas abiertas más tarde reunidas en libro, Las ciento y una, donde un Sarmiento furioso obtura al habitual y brillante sostenedor de argumentos.

16 La relación tensa que se establece entre estas superficies textuales diferentes es uno de los tantos niveles en que se verifican los vaivenes de la subjetividad que aparece en la construcción de imagen llevada a cabo por Sarmiento. 
Toda carta - se sabe- establece un esquema de comunicación en tiempo diferido. Para ello se requiere de una fuerte presencia en el texto de la imagen de aquel a quien se remite. Como contraparti$\mathrm{da}$, esta presencia del destinatario sostiene y otorga autoridad al remitente. Con la incorporación de correspondencia a su cuerpo, Campaña en el Ejército Grande manipula esta convención del género epistolar para legitimar al yo-Sarmiento que (se) escribe. Un ejemplo paradigmático en este sentido lo constituye la carta por la cual el autor dedica - en el doble sentido de dedicatoria y de dedicación- su libro a Juan Bautista Alberdi.

Fechada en Yungay el 12 de noviembre de 1852, la carta-dedicatoria se abre con la evocación de una situación de comunicación pretérita entre ambos sujetos. El Sarmiento que remite dibuja el espacio que reclama para que su texto se instale. Así, la carta viene a continuar la situación iniciada "en tres días de conferencias", cuando el sujeto que enuncia asumió una posición mantenida "en veinte cartas por lo menos". Se condensa de este modo una aspectualización imperfectiva que opera con poder clasemático en la temporalidad de la enunciación de Campaña en el Ejército Grande. El aspecto imperfectivo viene a reforzar la autoridad del sujeto que enuncia (un sujeto que se mantiene idéntico a sí mismo durante una situación enunciativa prolongada), al tiempo que fortalece el valor de verdad de sus enunciados. Además, esta aspectualización de la temporalidad imaginaria contribuye a la textualización del contexto de producción de esta escritura. En la polémica, como locus de enunciación, estaría operando una doble temporalidad imaginaria caracterizada por los diferentes aspectos que modalizan con un fuerte impacto en la producción de significaciones. Por un lado, los enunciados vehiculizados en el espacio de la polémica construirían una aspectualización perfectiva de la temporalidad, otorgando a los significados una impronta de clausura. Por otro, la temporalidad de la enunciación propiamente dicha encontraría en el imperfecto un aspecto clasemático, manteniendo la polémica como un espacio no obturado, como un presente continuo.

Las características de la polémica como modalidad del discurso ponen en primer plano las relaciones que se traman entre los enunciadores en términos de los lugares que ocupan. De este modo, los enunciados que circulan impactan sobre las figuras de los locutores de una manera más notable que en otras formas discursivas, estableciéndose un juego de espejos que reflejan y refractan significaciones, 
espesando las imágenes de los sujetos de la enunciación. Este procedimiento se potencia en aquellos enunciados donde la polémica habla de sí misma: al volverse la propia enunciación (la polémica) contenido de los enunciados, se instala un alocutario fuerte que, oblicuamente, define, fortalece y legitima la autoridad de quien enuncia. La carta de Sarmiento a Alberdi reflexiona sobre Campaña en el Ejército Grande en cuanto objeto que se produce y circula en términos polémicos:

[...] No será el timbre menor de su talento y sagacidad el haber provocado y hecho necesaria esta publicación, pues cónstale a V., a todos mis amigos aquí, y al señor Lamas en Río de Janeiro, que era mi ánimo no publicar mi Campaña hasta pasados algunos años. Los diarios de Buenos Aires han reproducido el Ad Memorandum que la precede, el prólogo y una carta con que se lo acompañé al Diario de los Debates. Véalas V. en el Nacional, y observe si hay consistencia con mis antecedentes políticos, nuestras conferencias en Valparaíso y los hechos que voy a referir. (Sarmiento, Campaña 118)

Talentoso y sagaz, Alberdi apresura la publicación porque se trata de un interlocutor potente que instaura el polemos al desviarse del lugar que la carta imagina como origen: la conveniencia de permanecer al margen en un periodo "en que el caudillaje iba a agotarse en esfuerzos inútiles por prolongar un orden de cosas de hoy más imposible en la República Argentina" (Sarmiento, Campaña 117). El desvío de Alberdi, su nueva colocación cercana a Urquiza, pone en crisis el diagrama anterior trazado sobre el ideologema civilización frente a barbarie; y es en este efecto desestabilizador donde la figura de Alberdi gana densidad. En su acercamiento a Urquiza, Alberdi revela lo inestable de un equilibrio fundado y sostenido sólo por la permanencia de Rosas en el poder. Corrido Rosas de la escena, se abrieron los diques de contención, haciéndose visibles los puntos de fuga. El movimiento de Alberdi desestabiliza las certezas previas porque se trata de una operación de un alto valor semiótico, y de esta manera es presentado por Sarmiento en su carta. En última instancia, lo que se pone en juego en esta polémica es el poder de la semiosis: se trata de dos sistemas interpretativos en pugna por acceder al lugar de la hegemonía; el espacio de la civilización se transforma de este modo en el teatro de operaciones de la lucha por imponer un sistema de configuración de sentidos. 
Frente a la subjetividad de Alberdi, con sus deslizamientos por entre la porosidad de los espacios, Sarmiento se define como un sujeto con una posición nítida:

En la prensa y en la guerra V. sabe en qué filas se me ha de encontrar siempre, y hace bien en llamarme el amigo de Buenos Aires, a mí que apenas conocí sus calles, V. que se crió allí, fue educado en sus aulas, y vivió relacionado con toda la juventud. (Sarmiento, Campaña 118)

Una vez más, es el esquema civilización frente a barbarie el molde sobre el cual el sujeto se enuncia a sí mismo. Como es sabido, una de las variaciones de esta matriz fue la oposición entre Buenos Aires y el interior. Sarmiento se reconoce como "el amigo de Buenos Aires", como el amigo de la civilización. Al escribir "Buenos Aires", no se refiere la capital porteña, sino que convoca los sentidos de un ideologema - siempre el mismo- instalando su yo en el territorio de su significante. La dimensión ideológica de la operación se revela en la diferencia que reclama para sí respecto de Alberdi. La secuencia crianza-educación-juventud demarca los núcleos de la estructura de un relato biográfico para Alberdi a través del cual se lo asimila a un modelo subjetivo claramente delineado, a un tipo: Alberdi es el "porteño civilizado". Pero "el amigo de Buenos Aires" es quien apenas conoció las calles de la ciudad, y esta nominación es la apropiada: hace bien Alberdi en llamarlo de este modo, porque es Sarmiento quien encarna los verdaderos valores de la civilización. De esta manera, la posición del yo se afirma en el reconocimiento de un otro altamente legitimado.

El sistema de legitimación del sujeto que enuncia en Campaña en el Ejército Grande se articula como una serie de juegos de cajas chinas yuxtapuestos por contigüidad. Si, por un lado, las cartas textualizan sus destinatarios construyéndolos como subjetividades densas que autorizan la voz de quien remite, por otro lado, en el marco de la carta como situación de enunciación se expanden relatos que reponen aparatos enunciativos, narrativizándolos. De este modo, se dispara una mise en abîme que confiere volumen a los cuerpos que, en su contigüidad, traman la materialidad textual, como así también la autoridad de la instancia que enuncia.

La segunda entrega de Campaña estuvo constituida por un prólogo y una carta a Bartolomé Mitre. Fechada en Río de Janeiro el 13 de abril de 1852, la carta narra la estadía de Sarmiento en Petrópo- 
lis, "la linda colonia alemana sobre la montaña Das Orgas" (Sarmiento, Campaña 108), donde trabó amistad con el emperador Pedro II, quien recibió al argentino "con una indulgencia y atención que a veces le hacía derogar de las formalidades de la etiqueta" (108). En el relato de Sarmiento a Mitre, la relación con el Emperador se construye en términos de un intercambio de bienes simbólicos:

El Emperador, joven de veinte y seis años, estudioso, y dotado de cualidades de espíritu y de corazón que lo harían un hombre distinguido en cualquiera posición de la vida, se ha entregado con pasión al estudio de nuestros poetas, publicistas y escritores sobre costumbres y caracteres nacionales. Echeverría, Mármol, Alberdi, Gutiérrez, Alsina, etc., etc. son nombres familiares a su oído, y por lo que a mí respecta, habíame introducido favorablemente Civilización y barbarie, hace tiempo, con la primera edición, habiéndose procurado después Sud América, Argirópolis, Educación popular, etcétera. Mi recepción era, pues, favorecida por estos antecedentes, y en varias admisiones, muchas de ellas solicitadas, pues por temor de ser indiscreto yo economizaba mis visitas, he pasado horas enteras respondiendo a sus preguntas, explicándole las cosas que los escritos no alcanzan, dándole noticias sobre el paradero de los hombres cuyos nombres le han interesado. (Sarmiento, Campaña 109)

La historia de esta relación expande una situación comunicativa donde el interlocutor (Pedro II) aparece como un sujeto que se sostiene (y sostiene el vínculo con Sarmiento) en dos planos: uno político y otro intelectual. ${ }^{17}$ En un punto, la imagen de Pedro II que se diseña en la carta sostiene la autoridad del yo-Sarmiento mediante cierto funcionamiento especular:

[...] El Emperador seguía con interés el hilo de mis ideas, apoyando cada frase con un movimiento de cabeza en señal de afable

17 Dado el carácter del vínculo entre estas subjetividades (un vínculo que se inicia en el ámbito de lo público: en febrero de 1853 Pedro II condecoró a Sarmiento por su participación en el Ejército Grande aliado de Sud América), se trataría de una relación que atravesaría los espacios de lo público y lo privado, haciendo imprecisos sus límites. El borramiento de las fronteras entre lo público y lo privado es un problema que atraviesa el corpus de Campaña en el 
asentimiento, y dirigiendo de vez en cuando sus miradas hacia los individuos de su séquito, que escuchaban nuestra conversación, parecía decirles: “¿No oyen ustedes como es lo que yo les decía?" Felizmente este lenguaje de mi parte ni aires de lisonja tenía, ni era nuevo para el Emperador. (111)

Pedro II es presentado como un sujeto instalado en el espacio de lo político que exhibe (en el espacio de lo privado) un capital simbólico prestigioso y valorado, cuya propiedad lo coloca en una posición privilegiada para el ejercicio de sus funciones públicas. Es así como, a través de la figura del emperador, la carta propone un modelo de subjetividad autorizada para el manejo de la res publica, modelo donde se reconoce la imagen que Sarmiento quiere para sí. Los bienes simbólicos acumulados por Pedro II certifican la validez de su "afable asentimiento" como interlocutor del sanjuanino, una adhesión que ratifica los enunciados de Sarmiento confiriéndoles sustancia.

Es así como por la superficie de Campaña en el Ejército Grande proliferan situaciones comunicativas que se erigen en el andamiaje sobre el cual un yo-Sarmiento intenta autorizar un relato. Esta posición dominante del yo respecto de la materia narrada asegura el cumplimiento del objeto de la narración: "Contar con verdad los sucesos, grandes y pequeños" a los que esta subjetividad ha asistido como "precursor, colaborador, actor y testigo" (Sarmiento, Campaña 305). Una narración, entonces, que se propone abordar una serie de acontecimientos en términos de la experiencia de un sujeto. $\mathrm{Y}$ es en esta ligazón entre acontecimiento, subjetividad y experiencia el punto donde Campaña en el Ejército Grande se asocia a la autobiografía. ${ }^{18}$ Con esta maniobra, el texto cierra la operación

Ejército Grande, y se hace visible por el tenor de los textos que se insertan. Por un lado, la Campaña se articula mediante la yuxtaposición de materiales cuya definición en términos de publicidad y privacidad no es homogénea: en un mismo plano se incorporan textos como las cartas, destinados a circular por un espacio privado, y fragmentos de artículos periodísticos, cuya especificidad genérica estaría atravesada por su destinación a un circuito que se definiría como el grado máximo de publicidad. A esto se suma el hecho de que la incorporación de las cartas determina un evidente pasaje de escritura íntima al espacio público.

18 “El tema esencial de toda obra autobiográfica son realidades experimentadas de una forma concreta y no aquellas que forman parte del ámbito de 
puesta en juego por el escritor para intervenir en esta etapa del proceso histórico que lo tuvo como uno de sus protagonistas destacados. Para situarse en el origen de (y originando) un proyecto que diseña la figura del reformador letrado por medio de la crítica de un presente que se narra como la barbarie de los caudillos, este sujeto ejercita un doble movimiento: pone en escena un aparato formal que afirme y garantice su autoridad y legitimidad como enunciador, para luego asociar esta fuente de lenguaje debidamente acreditada a una matriz discursiva (lo autobiográfico) que contenga y otorgue densidad a las significaciones adheridas a este sujeto.

Acontecimiento, subjetividad y experiencia se enlazan en el trabajo de la memoria: un elemento activo que, en el presente de la escritura, reelabora los hechos en una formalización dadora de sentido. La memoria es un tema presente en el conglomerado de textos que definen la superficie de Campaña en el Ejército Grande. El “Prólogo", aparecido en El Nacional de Buenos Aires como parte de la segunda entrega de lo que más tarde sería el libro, aborda el problema de la memoria diseminando un haz de significaciones que trazan un posible mapa de lectura. Desde su inicio, el "Prólogo" convoca la memoria de manera directa:

Si alguno de los millares de argentinos que han recibido heridas graves en nuestras eternas luchas civiles, leyere estas páginas, recordará aquella extraña sensación que se experimenta al recobrar el uso de la razón, y abriendo los ojos no poderse dar cuenta de sí mismo y preguntarse interiormente ¿quién soy y qué lugares son estos? ¿por qué no puedo moverme, y qué fisonomías extrañas son las que me rodean? Hasta que, a fuerza de prolija investigación, halla en un extremo apartado de la memoria, entre no bien definidas reminiscencias, el recuerdo de un combate en que estaba dando una orden, y después... después no se acuerda más de nada. (Sarmiento, Campaña 101; las cursivas son mías)

las experiencias consideradas en sí mismas con independencia del sujeto que las ha llevado a cabo. Evidentemente la realidad externa forma parte de la experiencia pero esta se ve modificada por la propia vida interior. Todo ello conforma nuestra particular experiencia personal. Así, todo hecho externo alcanza un determinado grado de valor sintomático que se deriva de su absorción y reflejo internos" (Weintraub 19). 
Se presenta así la memoria como una instancia que vincula al sujeto con la colectividad, al tiempo que autoriza sus enunciados. En efecto, se apela a la memoria en cuanto espacio donde se inscribe un recuerdo que hace posible delimitar la zona de una experiencia compartida, en la búsqueda de una garantía que haga efectiva la verdad del habla de este sujeto. Si la memoria se compone como el relato del recuerdo de experiencias comunes, es porque por los enunciados circulan contenidos que exceden lo personal y se instalan en una dimensión netamente colectiva. Y es en este carácter colectivo donde descansa el valor de verdad del habla de este sujeto, un valor de verdad que opera en dos sentidos al mismo tiempo: legitimando el discurso de esta subjetividad frente a su potencial lectorado y recortando un espacio de alianzas posibles fundado en la experiencia compartida.

Ahora bien, en un campo como el de la política americana los dominios se confunden, los sujetos se desorientan y es entonces necesario acudir a alguna forma que haga posible la racionalización del trabajo de la memoria:

Sucédenle cosas a uno en la política americana que no sería extraño tomarse por despierto, bien despierto, por el negro del cuento, experimentando realmente aquella desorientación de que hablaba al principio; y vale la pena de contarlo, la fascinación, que, después de disipada, me ha inducido a poner orden por escrito a mis últimas reminiscencias. (Sarmiento, Campaña 101)

Una vez más, Sarmiento encuentra en la escritura una máquina de formalización de la experiencia, o de su recuerdo en este caso. El "Prólogo" construye una escena para el trabajo de la memoria. El sujeto narra su despertar en un cuarto, frente a una ventana que le revela un paisaje desconocido, exótico:

Este sol, esta vegetación, este lujo de habitaciones sólo puede verse en la India, en Madrás o en Calcuta, donde la cultura inglesa ha sometido a regla la naturaleza tropical, desenfrenada, bella y ebria como una bacante antigua. (102)

El despertar inmerso en la ajenidad dispara la pregunta del sujeto: “¿Dónde estoy?". Impedido de "tomar por el próximo extremo" el hilo de la propia existencia, comienza su búsqueda "un poco más allá" entre los recuerdos, llegando al momento en que, menos de 
seis meses antes del presente de la enunciación, un grupo de siete hombres "partían de Chile, rondando el Cabo de Hornos a bordo de la Médicis" a prestar sus servicios a Urquiza contra Rosas. De este modo, el sujeto valida su enunciación al sostenerla en una escena que garantiza la verdad autobiográfica porque se instala en un momento de certeza:

Por lo que a mí respecta, pues ya sabía quién era yo, traje a la memoria al volver a mi trascuerdo, que dejando atrás familia y cuidados de fortuna, en busca de una patria libre y culta, por quince años de destierro suspirada, había costeado el Atlántico y el Pacífico, remontando el majestuoso Uruguay y el fecundizante Paraná; atravesando las provincias argentinas, Entre Ríos y Santa Fe; visitando las capitales Montevideo y Buenos Aires; batiéndome en mar y en tierra; y viajando y combatiendo, soportando rudas fatigas, y gozando de emociones profundas; observando lo que mis ojos veían y oían mis oídos; pensando, escribiendo, y viviendo de la vida febril del entusiasmo y de la lucha; y como si algo faltara en este vivísimo panorama, pasado a mi vista en cinco meses de actividad y movimiento a los hielos del Cabo de Hornos, venían por añadidura a oponerse lo esplendores sofocantes del trópico y a las desnudas e ilimitadas planicies de las Pampas Argentinas, las sañudas cuestas y picos, que entre bosques enmarañados rodean la lujosa bahía de Río de Janeiro, donde escribo estas páginas, en el Catete, barrio pintoresco y fashionable, Hotel des Étrangers, en una habitación alegre cuyas ventanas dan hacia el pedazo de mar, contenido entre los faldeos de la montaña das Orgas, el Pan de Azúcar y el Corcovado, y era la tasa de agua que en parte caía bajo mis miradas al despertar, y no acertaba a comprender en el primer momento. (Sarmiento, Campaña 103; las cursivas son mías)

Para responder a la pregunta por el lugar que ocupa en el presente ("¿Dónde estoy?"), el yo (autos) acude a la historia de vida (bios) poniéndola en escritura (grafé). En cierto sentido, lo que narra la autobiografía es la posición actual del sujeto, su colocación en la comunidad, su lugar político, ${ }^{19}$ un relato que se autoriza en un saber del sujeto que otorga certezas: "ya sabía quién era yo".

19 “Toda consideración del papel asignado a la memoria en la escritura autobiográfica hispanoamericana exige el análisis de la posición del autobiógrafo cuando emprende el relato de su vida. El presente de la escritura sin duda condiciona el rescate del pasado; no cuenta tanto lo recordado, como cuándo se recuerda y a partir de dónde" (Molloy, Acto 186) 
Entonces, es la certeza de un sujeto que conoce su posición porque conoce su pasado el lugar desde donde se enuncia en Campaña en el Ejército Grande. Y es esto mismo lo que la carta que inaugura el libro pone en escena: en el corte que provoca toda escritura que se inicia, en su incipit el texto revela el punto desde donde se hablará. Se trata de la carta remitida por Sarmiento a José Santos Ramírez, ${ }^{20}$ fechada el 26 de mayo de 1848. La misiva se abre con la presentación de la memoria del primer encuentro entre ambos, y es interesante la manera en que el escrito compone esta escena original, ya que se organiza en torno de la definición de la asimetría posicional de estos sujetos: Ramírez era el jefe del ejército que había tomado a Sarmiento como prisionero.

Pero esta diferencia en las posiciones - definida en términos político-institucionales, esto es, como lugares diferenciados en el espacio de la comunidad - aparece trascendida por la mediación de una zona que ambos sujetos comparten. Los valores de Ramírez revelan en su subjetividad una dimensión ética que lo aleja de la moral de sus elecciones políticas: el militar salva a Sarmiento en un acto que hace visible un territorio de valores compartidos. Y son estos valores lo que redefinen, en el presente de la enunciación, el eje de la relación, ubicando a los sujetos en posiciones simétricas - "Hoy V. y yo somos prófugos, desterrados" (Sarmiento, Campaña 59) -, ambos enfrentados a Rosas, enfrentados a "ese sistema [...] contra la naturaleza, la justicia y el derecho" (60), enfrentados a la barbarie.

Campaña en el Ejército Grande define la posición de su enunciador en la certeza de un sujeto que conoce su colocación en la comunidad porque conoce su pasado. Se trata de una posición ideológica porque, en su representación, la comunidad es imaginada a través de un signo ideológico: la dicotomía civilización frente a barbarie, ideologema que se imprime sobre un colectivo, inventando la comunidad y delimitando su espacio. De esta forma, la comunidad

20 Habiendo servido a las órdenes de Quiroga, José Santos Ramírez en 1839 fue nombrado por Rosas coronel mayor del ejército de Buenos Aires. “En 1848 se hallaba refugiado en San Juan por distanciamientos con el gobernador de Mendoza. Para volver a la gracia de Rosas comunicó a éste la carta que Sarmiento le había enviado, que pudo ser utilizada para solicitar del gobierno de Chile que limitase las actividades conspirativas de Sarmiento" (nota 1 de la edición de Halperín Donghi de la Campaña en el Ejército Grande, 59). 
es representada como un universo fracturado en dos territorios irreconciliables, representación que atraviesa las subjetividades, modalizando la construcción de identidades. Así, el acto autobiográfico implica, necesariamente, un relato que atribuya al sujeto autofigurado un haz de atributos que defina su identidad mediante el lugar que ocupa en esa comunidad escindida por el ideologema que la constituye. Si la autobiografía narra la posición actual del sujeto, entonces debe narrar la historia del hombre civilizado o del bárbaro caudillo.

\section{Postdata}

Una primer interrogante organizó el punto de partida de estas notas: si, como sostienen ciertos desarrollos teóricos, la autobiografía es tanto un modo de leer tanto como de escribir, cuáles serían los rasgos textuales que permitiesen abordar una lectura de Campaña en el Ejército Grande de Sarmiento. La recurrencia del argumento crítico acerca del carácter autobiográfico que atraviesa los escritos sarmientinos reforzó la pregunta por aquellos aspectos de su escritura que convocarían la clave autobiográfica como protocolo de lectura. Esta inquietud fue perfilando la búsqueda de elementos que permitieran visualizar modalidades autobiográficas en la producción del autor, y así intentar el esbozo de una máquina de lectura que, como herramienta crítica, habilitara el intento de visualizar, desde esta perspectiva, zonas de un texto que no responde linealmente a las convenciones del género autobiográfico. En ese sentido, la indagación de Recuerdos de provincia - como el texto propiamente autobiográfico de Sarmiento, pero también en su carácter de modelo del género en el campo cultural argentino del siglo XIX - apareció como un primer ejercicio no por obvio poco necesario. Así, en la lectura de este escrito modélico, al igual que en ciertas operaciones ejercidas por la crítica sobre él, fue posible demarcar y poner el acento en un conjunto de estrategias que invitaban a ser leídas como la puesta en escena de un locus enunciativo que imaginaba un locutor hablando de sí mismo bajo la modalidad de un relato que presentaba la forma de una crítica de su presente narrado como la barbarie de los caudillos. Esta crítica del presente aparecía tramada con un proyecto de Estado sostenido en un enunciador que para ganar espesor apelaba a la expansión de una narratividad autobiográfica. A partir de ahí, el recorrido por Campaña en el Ejército 
Grande encontraba un mapa que permitía formular al texto preguntas en torno de las modalidades a las que recurría para instalar un sujeto con el espesor necesario para garantizar la efectividad de sus enunciados, y con base en estos examinar las relaciones que se establecían entre subjetividad, acontecimiento y experiencia. Este modo de interpelación fue organizando atribuciones de sentido donde modalidades propias de lo autobiográfico se ligaban a la narración de la colocación en la comunidad del sujeto de la enunciación. Emergió así una línea narrativa que imagina la comunidad representándola (construyéndola) a partir del clásico ideologema decimonónico civilización frente a barbarie, y colocando al sujeto que se autofigura ocupando la posición del hombre civilizado.

¿Cuál es la significación que esta imagen adquiere en el contexto de escritura de Campaña en el Ejército Grande? Fracturado el campo antirrosista tras la caída del dictador porteño, el espacio de la "civilización" perdió su punto de enlace. Las diferencias estratégicamente silenciadas por la coyuntura del periodo de Rosas empezaron a hacerse oír redefiniendo alianzas y lealtades. La civilización se desterritorializó al dispararse sus puntos de fuga, y las certezas que articulaban el campo perdieron su capacidad de cohesión y su poder legitimador de enunciaciones posibles.

En este nuevo estado de cosas, la figura de Urquiza ya no representa "la gloria más alta de la Confederación"; Urquiza es quien hace "sentir a los emigrados argentinos la necesidad de ponerse la cinta colorada", ${ }^{21}$ prolongando, desde la perspectiva de Sarmiento, un orden de cosas "de hoy más imposible en la República Argentina." En este contexto, el acercamiento de Alberdi a Urquiza es la imagen que condensa la crisis de los sentidos que articulaban la civilización como un proyecto estatal con cierto grado de homogeneidad. Frente a esto, Sarmiento fortalece su construcción de imagen mediante operaciones que lo presenten como la única alternativa frente al peligro de la barbarie. Así, se compone como la encarnación de los valores de la civilización apelando a modalidades autobiográficas: muestra la propia vida como el modelo de una vida civilizada.

21 La cinta colorada fue el distintivo utilizado por los federales de las Provincias Unidas del Río de la Plata. Durante el período rosista, la cinta se convirtió en el emblema del régimen autoritario instalado por el dictador porteño. 
Bibliografía

Sarmiento, Domingo Faustino. Campaña en el Ejército Grande aliado de Sud América. Ed. Tulio Halperín Donghi. Bernal: Universidad Nacional de Quilmes, 1997.

. Facundo o civilización y barbarie. 1845. Caracas: Biblioteca Ayacucho, 1977.

. Mi defensa. 1843. Buenos Aires: Gleizer, 1927.

. Recuerdos de provincia. 1850. Buenos Aires: Sopena, 1961.

Alberdi, Juan Bautista. Bases y puntos de partida para la organización política de la República Argentina. 1852. Buenos Aires: CEAL, 1992.

—. Obras selectas. 2 vols. Buenos Aires: La Facultad, 1920.

Altamirano, Carlos y Beatriz Sarlo. "Una vida ejemplar: la estrategia de Recuerdos de Provincia." Ensayos argentinos. De Sarmiento a la vanguardia. Ed. Carlos Altamirano y Beatriz Sarlo. Buenos Aires: CEAL, 1983.

Bourdieu, P. "Campo intelectual y proyecto creador." Problemas del estructuralismo. México: Siglo XXI, 1967.

Bruss, Elizabeth. "Actos literarios." Anthropos. Monografías temáticas No. 29: La autobiografía y sus problemas teóricos. Estudios e investigación documental. Barcelona: Anthropos, 1991.

Eakin, Paul John. "Autoinvención en la autobiografía: el momento del lenguaje." Anthropos. Monografías temáticas No. 29: La autobiografía y sus problemas teóricos. Estudios e investigación documental. Barcelona: Anthropos, 1991.

Gramuglio, María Teresa. "La construcción de la imagen." Héctor Tizón et al. La escritura argentina. Santa Fe: Universidad Nacional del Litoral y Ediciones de la Cortada, 1992. 37-64.

Gusdorf, Georges. "Condiciones y límites de la autobiografía." Anthropos. Monografías temáticas No. 29: La autobiografía y sus problemas teóricos. Estudios e investigación documental. Barcelona: Anthropos, 1991. 
Halperín Donghi, Tulio. "Lamartine en Sarmiento: Les Confidences y Recuerdos de provincia." Filología. Buenos Aires: 20.2 (1985):177190.

- "Prólogo." Domingo Faustino Sarmiento. Campaña en el Ejército Grande aliado de Sud América. Buenos Aires: Universidad Nacional de Quilmes, 1997.

Jitrik, Noé. Muerte y resurrección de Facundo. Buenos Aires: CEAL, 1983.

Lejeune, Philippe. "El pacto autobiográfico." Anthropos. Monografías temáticas No. 29: La autobiografía y sus problemas teóricos. Estudios e investigación documental. Barcelona: Anthropos, 1991.

Loureiro, Ángel. "Problemas teóricos de la autobiografía." Anthropos. Monografías temáticas No. 29: La autobiografía y sus problemas teóricos. Estudios e investigación documental. Barcelona: Anthropos, 1991.

Ludmer, Josefina. El género gauchesco. Un tratado sobre la patria. Buenos Aires: Sudamericana, 1988.

Martínez Estrada, Ezequiel. Sarmiento. Buenos Aires: Sudamericana, 1969.

Misch, Georg. "El problema de la verdad en la autobiografía." Revista del Instituto de Filosofía. Universidad Nacional de Córdoba, 1957.

Molloy, Sylvia. Acto de presencia. La escritura autobiográfica en Hispanoamérica. México: El Colegio de México/FCE, 1986.

. (1982) "Inscripciones del yo en Recuerdos de provincia". Sur. 350-351 (1982): 131-140.

_ "Sarmiento, lector de sí mismo en Recuerdos de provincia." Revista Iberoamericana 143 (1988): 407-418.

Nowak, William J. "La personificación en Recuerdos de provincia: la despersonalización de D. F. Sarmiento." Revista Iberoamericana 143 (1988): 585-602. 
Olney, James. "Algunas versiones de la memoria / Algunas versiones del bios: la ontología de la autobiografía." Anthropos. Monografias temáticas No. 29: La autobiografía y sus problemas teóricos. Estudios e investigación documental. Barcelona: Anthropos, 1991.

Prieto, Adolfo. La literatura autobiográfica argentina. Buenos Aires: CEAL, 1982.

Ramos, Julio. Desencuentros de la modernidad en América Latina. Literatura y política en el siglo XIX. México: Fondo de Cultura Económica, 1989.

_. "Escritura y oralidad en el Facundo." Revista Iberoamericana 143 (1988): 551-572.

Rosa, Nicolás. El arte del olvido. Buenos Aires: Puntosur, 1991.

Shumway, Nicolás. La invención de la Argentina. Historia de una idea. 2a. Ed. Buenos Aires: Emecé, 1995.

Stratta, Isabel. "El género autobiográfico en el siglo XIX." Desde la Colonia hasta el Romanticismo. Buenos Aires: CEAL, 1980. Vol. 1 de Historia de la literatura argentina. 5 vols. 1980.

Weinberg, Félix. "La época de Rosas. El romanticismo." Desde la Colonia hasta el Romanticismo. Buenos Aires: CEAL, 1980. Vol. 1 de Historia de la literatura argentina. 5 vols. 1980.

Weintraub, Karl. "Autobiografía y conciencia histórica." Anthropos. Monografías temáticas No. 29: La autobiografía y sus problemas teóricos. Estudios e investigación documental. Barcelona: Anthropos, 1991.

Zanetti, Susana y Margarita Pontieri. "El ensayo. Domingo F. Sarmiento." Desde la Colonia hasta el Romanticismo. Buenos Aires: CEAL, 1980. Vol. 1 de Historia de la literatura argentina. 5 Vols. 1980.

. "Facundo y Recuerdos de provincia." Desde la Colonia hasta el Romanticismo. Buenos Aires: CEAL, 1980. Vol. 1 de Historia de la literatura argentina. 5 vols. 1980. 